\section{Legados \\ africanos: palavra enunciadora de simbolismos étnicos}

DOI: https://doi.org/10.22481/odeere.v3i3.1571

\author{
Marise de Santana \\ Universidade Estadual do Sudoeste da Bahia \\ (UESB) \\ nabaia1960@gmail.com
}

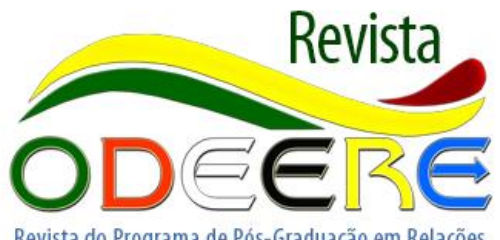

Revista do Programa de Pós-Graduação em Relações Étnicas e Contemporaneidade (PPGREC) - UESB
Resumo: As diferentes etnias produzem formas simbólicas, uma destas formas é através das imagens que a palavra enuncia, sendo assim, podemos afirmar que ao entrar em campo para estudar sobre etnicidades, o que os pesquisadores/as autores/as fazem é buscar entender quais formas simbólicas permeiam os universos estudados. Para pensar acerca desses universos é que tomo simbolismos étnicos enunciados pelas imagens que a palavra Legados Africanos carrega. A amplitude do trato com a categoria analítica legado africano pode se mostrar nas diversas obras de diferentes autores e autoras, estudiosos das etnias africanas no Brasil, seja nas dimensões da cultura, da religião, das questões raciais negras, da linguística e outras. Mas aqui, o propósito é tomar as produções monográficas escritas por alunas e alunos, os quais orientei no curso de Pós-Graduação Lato Sensu em Antropologia com Ênfase em Culturas Afro-brasileiras para entender esses universos simbólicos. Neste sentido que, durante as orientações estava a lhes alertar que um curso de Antropologia com Ênfase em Culturas Afro-brasileiras, não poderia desprezar a categoria central de análise e interpretação que é legado africano no Brasil, salvo se, e somente se, a metodologia tratasse do objeto numa abordagem reducionista que excluísse, negasse e silenciasse as reminiscências africanas. As produções elaboradas por esses discentes nos indicou que os simbolismos presentes na palavra legados africanos enunciam que não 
são vistos como saberes de pertencimento étnico e sim como crenças.

Palavras-Chave: Patrimônio Africano, Representações simbólicas, Cultura Afrobrasileira.

\section{African legacies: the enunciation of ethnic symbolisms}

Abstract: Different ethnic groups create symbolic representations. One such represention comes in the form of images expressed in words. In this way, we can say that upon entering the field to study the diverse ethnicities, the first thing a researcher or writer does is strive to understand which representations permeates the universe under consideration. And in order to approach such universe, I focus here on the ethnic representations evoked by the words "African Heritage". The significance of the treatment given to the investigation of this subject can be seen in the increasing number of works by diferent writers examining the African heritage in Brazil, be it in the cultural, religious, linguistic and/or race issues dimensions, among other ones.
My purpose here, though, is to take under consideration the papers produced by various students under my advisory during the Lato Sensu Graduation Program in Anthropology with a Special Track in AfroBrazilian Culture, with a view to understand these symbolic universes. It should be noted right from the the beginning that in my advisory work I have allways stressed the importance, for the program in Anthropology with a Track in Afro-Brazilian Culture, of never leaving aside from the investigation the central category of African Heritage, save if the methodological treatment deal with the subject in a reductionist way that excludes, denies or reduces to silence African reminiscences. One can see in the papers produced by these students that the symbolic representations contained in the words "African Heritage" are understood not as "ancient wisdom" and ethnic belonging, but rather as beliefs.

Keywords: African Heritage, Symbolic Representations, Afro-brazilian culture.

O estudo de legado africano entra na minha vida de pesquisadora de forma mais sistemática a partir das pesquisas para elaboração da dissertação de mestrado, logo depois se consolidando como pesquisa de doutorado. Então, lancei como problema de investigação nos estudos de doutorado o questionamento: como diante de suas opções religiosas, professores/as desenvolviam o trabalho docente em cidades em que mais fortemente o legado africano se 
apresentasse? Foi com esta indagação que em 2000, me lancei numa etno-pesquisa-ação ${ }^{1}$ coletando dados, com professores/as das cidades de Candeias e São Francisco do Conde, localizadas no Recôncavo da Bahia. Estas pesquisas resultaram na tese de doutorado intitulada "O Legado Ancestral Africano na Diáspora e a Formação Docente: Desafricanizando para Cristianizar". Aliado ao meu pertencimento, os estudos realizados no mestrado e doutorado me fundamentaram para desenvolver algumas ações dentro da instituição em que trabalho, neste sentido, entre muitos projetos que abarcava a temática Legado Africano, surge a proposta de um curso de Pós-graduação Lato Sensu em Antropologia com Ênfase em Culturas Afro-brasileiras.

As (14) quatorze monografias que orientei estão no acervo da biblioteca do $\operatorname{ODEERE}^{2} \mathrm{e}$ são assim intituladas: 1) "Reconstrução da Memória Histórica de Alguns Terreiros em Jequié/Ba", Almerindo Pimentel da Silva Júnior; 2) “Um Lugar para o Orixá: A Saga de Quem Busca Candomblé Fora de Sua Cidade", Valdinéia de Oliveira dos Santos; 3) "O Ilê Axé Ode Yá Minibú: Tradição Oral e a Preservação da Pertença”, Daniela Silva Santana; 4) "Contribuições do Grupo Capoeira Angola Palmares Para a Formação Cultural da Cidade de Jequié/Ba com a Dança Maculelê", Dinamérica Alves Teixeira; 5) "Ensino de História e Cultura Afro-brasileira: Um Estudo em Escolas Municipais de Jequié/BA", Edieme Pereira Matos Range; 6) "A Lei 10639/2003: Um Estudo em Escolas Municipais de Jequié/BA", Lúcia Maria de Souza Batista; 7) “Entre Caminhos, Narrativas, Cotidiano e Memórias: O Legado Africano na Formação Cultural do Bairro do Pau Ferro, Jequié/BA", Adriana Silva Barbosa; 8) "Encruzilhada de Saberes: Religiosidade e Dupla Pertença no Camamuzinho /Distrito de Ibirapitanga/Ba", Cristiane Batista da Silva Santos; 9) Edneide Alves Nascimento Putumujú, "O Legado dos Falares Afro-brasileiros em Ipiaú: Um Documento Vivo na Oralidade dos Idosos da Av. São Salvador- 'FUÁ'”"33; 10) "Ewé Awo: Um Estudo Antropológico Sobre As Folhas e

\footnotetext{
${ }^{1}$ No momento da pesquisa eu argumentava apenas que a metodologia envolvia alunos/as, professores/as de um curso de pedagogia das cidades pesquisadas, em que assumi uma turma, com o objetivo de trabalhar com pesquisaação ao tempo que junto aos alunos/as - professores/as, nós buscávamos fazer a etnografia das cidades, especialmente, focando o tema legado deixado pelos africanos trazidos escravizados para as referidas cidades. Portanto, a metodologia tinha sido escrita colocando os métodos da Etnografia e da Pesquisa-ação, só quando terminei a escrita da tese, li o livro "A Etnopesquisa Crítica e Multirreferencial nas Ciências Humanas e na Educação" de Roberto Sidnei Macedo (2005), em que o referido autor vai falar sobre Etno-pesquisa-ação na formação docente. Naquele momento entendi que ao juntar os dois métodos para envolver os docentes na pesquisa e trabalhar no sentido de rever valores de nossas formações, o que desenvolvemos enquanto método foi a Etno-pesquisa-ação.

${ }^{2}$ Órgão de Educação e Relações Étnicas da Universidade Estadual do Sudoeste da Bahia.

${ }^{3}$ Orientei este trabalho na qualidade de co-orientadora.
}

Odeere: revista do programa de pós-graduação em Relações Étnicas e Contemporaneidade - UESB. ISSN 2525- 4715. Ano 2, número 3, volume 3, Janeiro - Junho de 2017. 
Seus Segredos No Terreiro Ilê Axé Ogum Megê Em Vitória Da Conquista - Ba", Pedro Freire Botelho; 11) "Baianas do Acarajé: O Que Resta do Mito Africano nos Tabuleiros do Comércio Jequieense", Emanoel Jorge Leal Braga; 12) "Preservação do Legado Africano Pelas Mulheres Negras de Itagibá", João Nascimento de Souza; 13) "O Trabalho do docente nas aulas de história e culturas Africanas e Afro-brasileira em Camamuzinho - Ibirapitanga - BA", Zuleide Maria dos Santos; 14) "O Legado Africano em Itajurú- Jequié/BA", Joelma Brito Silva.

Sobre Legado Africano (Santana, $)^{4}$ e $(\text { Santana })^{5}$, afirma que são saberes e práticas de diferentes grupos étnicos africanos escravizados, que no Brasil, reelaboraram seus saberes e práticas e os mesmos se apresentam como traços das culturas afro-brasileiras ${ }^{6}$, fora e dentro do espaço religioso.

No horizonte das Ciências Sociais, alguns são os pesquisadores e pesquisadoras que venho tomando, por apontarem em suas obras caminhos para entender os legados africanos no Brasil. Nina Rodrigues ${ }^{7}$, Querino ${ }^{8}$, Verger ${ }^{9}, \operatorname{Ramos}^{10}$, Santos ${ }^{11}$ e muitos outros iluminaram minha caminhada de pesquisadora desta temática.

Todavia, preocupada com os universos simbólicos que a palavra Legados africanos carrega, me volto para os estudos de Roger Bastide ${ }^{12}$. Com o objetivo de discutir sobre a epistemologia africana, o autor fornece condições específicas para nossas análises, tomando o princípio da teoria da participação a partir de seus estudos sobre "Mentalidade Primitiva", obra clássica de Lévy-Bruhl. Bastide argumenta que, esses saberes tradicionais seguem um princípio

\footnotetext{
${ }^{4}$ SANTANA, Marise de. O Legado Africano na Diáspora e o Trabalho Docente: Desafricanizando para Cristianizar. Tese de doutorado. PUC, 2004.

${ }^{5}$ SANTANA, Marise de. O Africano e o Trabalho Docente IN: Inclusão Social, Identidade e Diferença: Perspectiva Pósestruturalistas de análise social. (Orgs) Amaral Jr., Aécio / Burity, Joanildo de A. São Paulo: Annablume, 2006.

${ }^{6}$ SANTANA, Marise de. ODEERE: Formação docente, linguagens visuais e legados africano no Sudoeste baiano. Vitória da Conquista: Edições UESB, 2014.

${ }^{7}$ RODRIGUES, Nina. O Animista Feitchista dos Negros Baianos . Rio de Janeiro: Civilização Brasileira S. A. , 1935.

${ }^{8}$ QUERINO, Manuel. Costumes africanos no Brasil. Organização e prefácio de Raul Lody. Recife: FUNDAJ, Editora Massangana, FUNARTE, 1988.

${ }^{9}$ VERGER, Pierre. Notas sobre o culto aos orixás e voduns na Bahia de todos os Santos, no Brasil e na antiga Costa dos Escravos, na África.. Tradução de Carlos Eugênio Marcondes de Moura. São Paulo: Editora da Universidade de São Paulo, 1999.

${ }^{10}$ RAMOS, Arthur. Introdução à Antropologia Brasileira: As Culturas negras. vol III. Rio de Janeiro, Guanabara: Livraria Editora da Casa do estudante do Brasil.

${ }^{11}$ SANTOS, Juana Elbein dos. Os Nagôs e a morte: Padê, Asésé e o culto Égun na Bahia. Petrópolis: Vozes, 1976.

${ }^{12}$ BASTIDE, Roger. Os Candomblés da Bahia rito Nagô. São Paulo: Companhia das Letras, 2001.
} 
que não é aleatório, assim, o autor nos diz que são princípios regidos pela lei de participação. Sobre a lei de participação ele afirma:

Para que a participação se estabeleça entre um homem, um objeto, uma planta, uma divindade etc., é preciso que obedeça a certas condições bem determinadas (...). A participação não se opera em qualquer direção, é orientada, segue linhas (...) em resumo, a participação pressupõe toda uma manipulação sagrada. ${ }^{13}$

As condições às quais Bastide se refere, está no plano do material e imaterial, portanto por elementos enunciados pelos simbolismos que nos remete a pensar acerca das imagens que as palavras carregam.

João Nascimento de Souza" ${ }^{14}$, estudando sobre as "Mulheres negras em Itagibá e suas contribuições para a preservação do Legado Africano", traz grandes contribuições para se pensar acerca da mestiçagem. Segundo ele, alguns moradores mais antigos afirmam ter encontrado neste território, a presença de índios, ainda que em pequenos grupos, que logo desapareceram. Entrevistando mulheres, suas pesquisadas, ele toma depoimentos que falam das matrizes indígena, africana e europeia, embora através destes depoimentos se perceba que existem constrangimentos para assumir a descendência africana e indígena, enquanto que os descendentes de europeus falam de suas ascendências com mais detalhes. Os elementos de pertencimentos, como religião e outros saberes, também são falados sob a ótica do "bom senso"15 cristão.

Assim, Nascimento na "conclusão" de seu texto, afirma que o Legado Africano em Itagibá "vive ao longo de décadas, enfrentando (...) intolerâncias religiosas ou fundamentalismos que só levam a destruir o que o ser humano tem de mais sagrado, a cultura".

A pesquisa de Nascimento toma as vozes dos sujeitos para indicar suas origens étnicas. Tal pesquisa reafirma a necessidade de nos voltarmos para ouvir as vozes dos mais velhos da

\footnotetext{
${ }^{13}$ Idem (p. 256).

${ }^{14}$ SOUZA, João Nascimento de. Preservação do Legado Africano Pelas Mulheres Negras de Itagibá. Monografia do Curso de Pós-graduação Lato Sensu em Antropologia com Ênfase em Culturas Afro-brasileira. Universidade Estadual do Sudoeste da Bahia-UESB, Jequié, 2010.

${ }^{15}$ GEERTZ, Clifford. O Saber Local: novos ensaios em antropologia interpretativa; tradução de Vera Mello Joscelyne. Petrópolis, RJ: Vozes, 1997.
}

Odeere: revista do programa de pós-graduação em Relações Étnicas e Contemporaneidade - UESB. ISSN 2525- 4715. Ano 2, número 3, volume 3, Janeiro - Junho de 2017. 
cidade, bem como de entrar no cotidiano para ouvir sobre os mitos, pesquisas em que seus princípios basilares sejam a oralidade.

Vejamos a produção da pesquisadora Dinamérica Alves Teixeira Guimarães ${ }^{16}$, em que ela investiga como o "grupo capoeira Angola Palmares propaga e contribui para a formação Cultural da Cidade de Jequié com a Dança Maculelê".

Esta pesquisa não se refere a esta manifestação da cultura, como legado deixado pelo africano para seus descendentes nesta cidade; sua hipótese é que o Maculelê veio de Santo Amaro da Purificação, cidade situada na região do Recôncavo Baiano. Os dados coletados não são enunciados indicando os elementos que foram agregados ao Maculelê em solo Jequieense; todavia, considero que esta pesquisa é de fundamental importância para situar a presença africana em Jequié, bem como a rejeição deste legado.

Guimarães salienta que os elementos que compõem o Maculelê são: a dança, o movimento do corpo, a batida das Grimas, as cantigas de louvação, a arte. Segundo ela, tudo isso acontece através do ritmo do agogô e do som dos atabaques.

Ela descreve: "As Grimas chocam-se com energia, em golpes denominados de Grimas e contra esgrimas". Quando o grupo faz suas apresentações em praça pública da cidade de Jequié, ficam em semicírculo "sempre batendo as Grimas, parando ao apito tradicional do mestre, e então sob o silêncio geral, entoam os cânticos de louvação". Ela prossegue descrevendo que "Tão logo terminada a louvação, eleva-se o coro, apoiado pelo rufar dos atabaques e pelas batidas das Grimas". Daí ela dizer que "Grimas", são bastões de madeira, pedaços de pau de 50 a $60 \mathrm{~cm}$ com um nó na ponta para apoiar a mão.

Falar sobre estes bastões como 'grimas', nos leva a pensar que provavelmente, "grimas" seja uma contração da palavra "esgrima", que corresponde ao esporte europeu praticado com o uso de florete. Neste sentido, o bastão ser chamado de 'Grimas' pode ser pensado como um dos elementos do maculelê que foi incorporado em solo de uma cidade que recebeu imigrantes italianos.

\footnotetext{
${ }^{16}$ GUIMARÃES, Dinamérica Alves Teixeira. Contribuições do Grupo Capoeira Angola Palmares Para a Formação Cultural da Cidade de Jequié/Ba com a Dança Maculelê. Monografia do Curso de Pós-graduação Lato Sensu em Antropologia com Ênfase em Culturas Afro-brasileira. Universidade Estadual do Sudoeste da Bahia-UESB, Jequié, 2007.
}

Odeere: revista do programa de pós-graduação em Relações Étnicas e Contemporaneidade - UESB. ISSN 2525- 4715. Ano 2, número 3, volume 3, Janeiro - Junho de 2017. 
A pesquisadora de falares africanos na Bahia, Yeda Pessoa de Castro ${ }^{17}$, diz que Maculelê "é uma dança do bate-pau, espécie de dança guerreira do folclore baiano, típica da cidade de Santo Amaro, na região do Recôncavo", mas também afirma que a palavra Maculelê é de origem banta.

Em função da minha origem de filha de uma cidade do Recôncavo da Bahia- Candeias, situada a uns $30 \mathrm{~km}$ da cidade de Santo Amaro da Purificação, sempre me referi ao maculelê como ouvia meus mais velhos falarem, "brincadeira". Nesta "brincadeira" os iniciantes usam cacetes (pedaços de pau de forma roliça e grossa) ou facão, usado somente por pessoas já experientes. Em nenhum momento ouvi qualquer referência a "grimas".

Já o facão, assim como os instrumentos de ferro, são elementos da natureza que têm simbologia referida ao Orixá guerreiro, Ogum, das culturas africanas e afro-brasileiras. É interessante lembrar que os mitos africanos e afro-brasileiros que falam de Inquices, Voduns e Orixás, trazem sempre a dualidade, de serem, elementos da natureza e também heróis civilizatórios. Ogum é o guerreiro que se veste com folhas de palmeira desfiadas, denominadas de Mariwô.

Um entrevistado de Guimarães afirmou, "não consigo ver o maculelê como proveniente de uma única etnia e sim uma dança com a contribuição destes três povos", e explicitou os povos aos quais se referia, "colonizadores portugueses, índios e negros".

É interessante dizer que, antropologicamente, maculelê vai ser 'dança' para uns, 'brincadeira' para outros, isto porque, tanto a dança como a brincadeira fazem parte da dialética que está presente na estruturação do movimento corporal. Na cosmovisão de um pensamento que une saberes, como o africano, dança e brincadeira não são excludentes, são complementares.

Ainda nos reportando à produção monográfica de Guimarães, podemos dizer que as palhas da costa que substituem o Mariwô na confecção das roupas do grupo de maculelê, alguns termos utilizados como, por exemplo, "grima" ao invés de "cacete", são outros tantos elementos de diferentes grupos étnicos que recriam o mito do maculelê no contexto da cidade de Jequié. No entanto, a discussão de mestiçagem não aparece.

\footnotetext{
${ }^{17}$ CASTRO, Yeda Pessoa. Falares Africanos na Bahia. Salvador: EDUFBA, 2004.
} 
A análise desta monografia aponta que quem muito bem percebe a mestiçagem na "dança do maculelê", com estruturação forte nas culturas africanas, são os protestantes. Vejamos o depoimento que Guimarães transcreveu de um dos seus entrevistados:

Os grupos evangélicos fazem uma ligação do maculelê com as religiões de origem africana, como o Candomblé e por esta razão não permitem que seus filhos participem. E ainda influenciam outros jovens para que desistam da dança ${ }^{18}$.

Este é um depoimento muito importante e que leva ao seguinte questionamento: como se relacionam, no interior do campo étnico, as diferentes identidades encontradas nestas cidades onde ocorreram as pesquisas?

O texto de produção de Emanoel Jorge Leal Braga ${ }^{19}$, "Baianas do Acarajé: o que resta do mito Africano nos Tabuleiros do Comércio Jequieense", embora não tendo trilhado de forma intensa pela metodologia de boca a ouvido, faz uso de uma bibliografia muito interessante e de alguma forma responde aos questionamentos formulados no parágrafo anterior.

O estudo feito por Braga aponta que nesta cidade, as baianas de acarajé buscam se distanciar dos mitos africanos que falam do acarajé. Um dos mitos do acarajé diz que esta é a comida votiva de lansã. É uma iguaria africana feita com feijão fradinho e cebola. Estudos nos apontam que esta iguaria começou a ser feita para vender nos tabuleiros por mulheres africanas e suas descendentes. Tais iguarias foram e são importantes como produtos que veiculam no comércio ambulante para sustentação financeira. Sendo o mito localizado na mitologia africana e também na religião afro-brasileira, alguns vendedores/as que são protestantes, pentecostais, neopentencostais e neo-protestantes, ressignificam o mito falando em "bolinho de Jesus". Já outros/as vendedores/as de acarajé, inclusive da religião afro-brasileira, negam o mito africano para atender ao "bom senso" de uma sociedade cristã que demoniza a cultura africana e afro-

${ }^{18}$ GUIMARÃES, Dinamérica Alves Teixeira. Contribuições do Grupo Capoeira Angola Palmares Para a Formação Cultural da Cidade de Jequié/Ba com a Dança Maculelê. Monografia do Curso de Pós-graduação Lato Sensu em Antropologia com Ênfase em Culturas Afro-brasileira. Universidade Estadual do Sudoeste da Bahia-UESB, Jequié, 2007, (pág. 33).

19 BRAGA, Emanoel Jorge Leal. Baianas do Acarajé: O Que Resta do Mito Africano nos Tabuleiros do Comércio Jequieense. Monografia do Curso de Pós-graduação Lato Sensu em Antropologia com Ênfase em Culturas Afrobrasileira. Universidade Estadual do Sudoeste da Bahia-UESB, Jequié, 2009.

Odeere: revista do programa de pós-graduação em Relações Étnicas e Contemporaneidade - UESB. ISSN 2525- 4715. Ano 2, número 3, volume 3, Janeiro - Junho de 2017. 
brasileira. Então, quando são perguntadas sobre a origem do acarajé, dissimulam o conhecimento para não afastarem seus fregueses.

Fica evidente que há um processo de recusa em associar o acarajé à sua origem africana, tanto no grupo que chama o acarajé de "bolinho de Jesus", como no grupo que usa o "bom senso" para anunciar o produto.

O uso do "bom senso" cristão também está presente na trajetória de mulheres que precisam se iniciar nas religiões de matriz africana em Ubatã/BA. Estes dados foram levantados por Oliveira Santos ${ }^{20}$, que fez um estudo etnográfico constatando que as mulheres procuravam se iniciar no candomblé em outras cidades, desta forma utilizando-se do afastamento temporário para esconder seu pertencimento. Neste estudo, ela indaga sobre as mulheres que desde a década de 1960 viajam para outras cidades a fim de iniciar-se nas religiões de matriz africana, deixando em suas cidades filhos e marido.

$\mathrm{Na}$ caminhada destas mulheres, as ordens religiosa e sexual estabelecidas vão agir excluindo-as por serem de uma religião que não obedece a ordem estabelecida pelo cristianismo, ao tempo que também as excluem por se ausentarem da sua casa, dos seus filhos, do seu marido, para viajar e passar até vinte dias longe de casa, o que não era um comportamento comum às mulheres casadas, de uma cidade pequena do interior do Sul da Bahia, no final da década de 1960, numa sociedade sob a égide do coronelismo e dos papéis sexuais bem definidos em torno do poder masculino.

A discussão de Santos gira em torno de se pensar como naquela comunidade a religião afro-brasileira era questionada pela ordem socialmente estabelecida. Neste sentido, o que deveria pertencer ao âmbito doméstico, passava a ser público. Os homens da cidade diziam para os maridos das religiosas, "se fosse minha mulher eu não deixava ir".

O que estava em jogo não era apenas como poderiam continuar a manter sua posição masculina, se suas mulheres resolvessem também transgredir a ordem, mas, sobretudo, o questionamento sobre a religião afro-brasileira.

\footnotetext{
${ }^{20}$ SANTOS, Valdinéia de Oliveira dos. Um Lugar para o Orixá: A Saga de Quem Busca Candomblé Fora de Sua Cidade. Monografia do Curso de Pós-graduação Lato Sensu em Antropologia com Ênfase em Culturas Afro-brasileira. Universidade Estadual do Sudoeste da Bahia-UESB, Jequié, 2007.
}

Odeere: revista do programa de pós-graduação em Relações Étnicas e Contemporaneidade - UESB. ISSN 2525- 4715. Ano 2, número 3, volume 3, Janeiro - Junho de 2017. 
Daí Santos conclui dizendo que o candomblé foi efetivamente uma conquista feminina na cidade de Ubatã, pois as mulheres iam a cidades baianas como Nazaré das Farinhas, Teixeira de Freitas, Salvador, Gongogí, na ausência do marido. Todavia, ela salienta que é importante entender estas "migrações temporárias", como meio de fugir do preconceito do mundo cristianizado que demoniza os cultos afro-brasileiros. Ela ainda informa que o preconceito também constrói uma demanda de procura na cidade de Ubatã por pessoas que querem manter sua pertença religiosa em segredo e vêm de outras cidades para frequentar os terreiros de Ubatã.

Outra produção monográfica é a de Zuleide Maria dos Santos ${ }^{21}$, falando da comunidade Cristal em Camamuzinho, distrito de Ibirapitanga. Segundo ela, o legado africano presente "nas festas dos terreiros, nas ações das benzedeiras, nas rezas nas residências, nas comidas típicas, nas vestimentas, enfim, está até hoje presente em Camamuzinho".

Vale aqui ressaltar que, os textos monográficos pouco problematizaram por que nestas comunidades os legados africanos não são valorizados. Quais são as relações de poder vivenciadas pelos grupos étnicos nestas cidades? Em muitos trabalhos, os dados das pesquisas apontam que a referência de data para coleta de dados, foi tomada a partir da emancipação política das cidades.

Falar sobre a emancipação de uma cidade ou de alguém, traz consigo a ideia de que, se houve emancipação é por que se desenvolveu se afastou da origem. Nossa história do Brasil vem tomando estes momentos para enunciar apenas as memórias do que é considerado como superior, como desenvolvido, ou seja, afastado da identidade do envolvimento étnico. Pela literatura antropológica, o superior, o desenvolvido, não é o índio e nem o negro, mas o europeu. As literaturas que falam da vida destas cidades estão ancoradas nos fatos que falam dos "heróis" os que "emanciparam".

As análises feitas até esta parte da proposta nos dão dados para pensar sobre mestiçagem e relações interétnicas dos diversos grupos que estão no interior das cidades lócus de pesquisa dos autores/as das monografias.

\footnotetext{
${ }^{21}$ SANTOS, Zuleide Maria dos. O Trabalho do docente nas aulas de história e culturas Africanas e Afro-brasileira em Camamuzinho - Ibirapitanga - BA. Monografia do Curso de Pós-graduação Lato Sensu em Antropologia com Ênfase em Culturas Afro-brasileira. Universidade Estadual do Sudoeste da Bahia-UESB, Jequié, 2010.
}

Odeere: revista do programa de pós-graduação em Relações Étnicas e Contemporaneidade - UESB. ISSN 2525- 4715. Ano 2, número 3, volume 3, Janeiro - Junho de 2017. 


\section{As imagens que a palavra enuncia}

Sendo assim, vamos lançando mão dos dados coletados nas monografias para pensar como as palavras podem estruturar os mitos através da oralidade e o rito ações que podem materializar-se através das imagens. Isto nos aponta que mito/rito são complementares e que, toda palavra enuncia imagens.

Numa educação do encantamento, as palavras enunciam um poder de ação porque estão impregnadas de forças, as palavras mobilizam o axé, a força quando pronunciadas, o Ofó ${ }^{22}$. Conforme está dito nas produções monográficas de Santana ${ }^{23}$, Putumujú (Orientei este trabalho na qualidade de co-orientadora $)^{24}$, Botelho ${ }^{25}$, as palavras contam histórias e estão carregadas do poder daqueles que a proferem. O professor Sarmento, um grande amigo querido, que muito contribuiu com as reflexões realizadas dentro do ODEERE- Órgão de Educação e Relações Étnicas e que hoje mora no Orum, dizia: "a palavra serve para construir e destruir".

As imagens que as palavras enunciam, enquanto relação de implicação recíproca, permeiam o cotidiano dos povos de qualquer etnia. Tanto as imagens como a palavra realçam possibilidades de ser incluídas ou excluídas de um determinado contexto.

É importante não negar, ocultar ou naturalizar as imagens que uma palavra enuncia, todavia, esta é uma das problemáticas que emergem com a palavra legado africano. Esta palavra carrega consigo imagens que evoca mitos e ritos diferentes das que são sancionadas pela ordem cultural cristã, branca e maniqueísta, portanto europeizada.

\footnotetext{
${ }^{22}$ Palavra de encantamento.

${ }^{23}$ SANTANA, Daniela Silva. O Ilê Axé Ode Yá Minibú: Tradição Oral e a Preservação da Pertença. Monografia do Curso de Pós-graduação Lato Sensu em Antropologia com Ênfase em Culturas Afro-brasileira. Universidade Estadual do Sudoeste da Bahia-UESB, Jequié, 2007.

${ }^{24}$ PUTUMUUÚ, Edneide Alves Nascimento. O Legado dos Falares Afro-brasileiros em Ipiaú: Um Documento Vivo na Oralidade dos Idosos da Av. São Salvador- 'FUÁ'. Monografia do Curso de Pós-graduação Lato Sensu em Antropologia com Ênfase em Culturas Afro-brasileira. Universidade Estadual do Sudoeste da Bahia-UESB, Jequié, 2008.

${ }^{25}$ BOTELHO, Pedro Freire. Ewé Awo: Um Estudo Antropológico Sobre As Folhas e Seus Segredos No Terreiro Ilê Axé Ogum Megê Em Vitória Da Conquista - BA. Monografia do Curso de Pós-graduação Lato Sensu em Antropologia com Ênfase em Culturas Afro-brasileira. Universidade Estadual do Sudoeste da Bahia-UESB, Jequié, 2008.
}

Odeere: revista do programa de pós-graduação em Relações Étnicas e Contemporaneidade - UESB. ISSN 2525- 4715. Ano 2, número 3, volume 3, Janeiro - Junho de 2017. 
Joly ${ }^{26}$ falando sobre a função de linguagem da imagem, afirma que, de forma implícita ou explícita a imagem comunica a força de sua significação. Para ela a imagem pode servir de intercessão entre o homem e o mundo:

A função informativa (ou referencial), muitas vezes dominante na imagem, pode também ampliar-se em uma função epistêmica, proporcionando-lhe a dimensão de instrumento de conhecimento. Instrumento de conhecimento porque certamente fornece informações sobre os objetos, os lugares ou as pessoas, em formas visuais tão diversas quanto as ilustrações, as fotografias, os mapas ou ainda os painéis.

Portanto, a formulação de imagens acontece quando alguém vê ilustrações, fotografias, visualiza um mapa, canta ou ouve uma música, conta um mito, formula imagens. A subjetividade individual ao formular uma imagem parte de um modelo de abstração, constituindo-se em imagens simbólicas que naturalmente foram evocadas por símbolos de pertencimentos étnicos ${ }^{27}$.

Joly assegura que imagens e palavras se engendram, umas às outras, em um movimento sem fim, portanto, as palavras estão aí para nos provar que elas enunciam imagens podendo nutrir a imaginação. Afirma ainda que longe da imagem ser um flagelo ameaçador no mundo contemporâneo, ela é um meio de expressão e de comunicação.

Neste sentido, Ferreira ${ }^{28}$, em tese de doutorado, fotografa suas pesquisadas, mulheres participantes de festas populares da Bahia, vestidas com indumentárias (que podem ser estudadas no âmbito do que chamamos de legados africanos. Saias, batas, ojás, contas e outros pertences de suas identidades étnicas), para puxar em suas falas a memória das mesmas. Neste trabalho, está colocada a ideia que ao ver em suas imagens símbolos de seus pertencimentos, estas mulheres vão falar de suas histórias de vida. O que está na base do referido trabalho é a leitura de imagens feita a partir da análise das palavras que foram enunciadas através da oralidade destas mulheres.

Dessa forma, Joly e Ferreira, estão a afirmar que as imagens enunciam rituais vários, portanto, as palavras enunciam imagens e rituais de uma determinada etnia.

\footnotetext{
${ }^{26}$ JOLY, Martine. Introdução à Análise da Imagem. Tradução Marina Appenzeller. Campinas, SP: Papirus, 1996(coleção ofício de Arte e Forma).

${ }^{27}$ Pertencimento étnico se enuncia pelos símbolos que uma determinada pessoa ou grupo possui a partir de suas identidades étnicas. Sobre identidade étnica sugiro as leituras de Oliveira 2000 e 2006.

${ }^{28}$ FERREIRA, Edson Dias. Fé e Festa nos Janeiros da Cidade de Salvador-Bahia. Tese de doutorado defendida na Pontifícia Universidade Católica de São Paulo. São Paulo, 2004.
}

Odeere: revista do programa de pós-graduação em Relações Étnicas e Contemporaneidade - UESB. ISSN 2525- 4715. Ano 2, número 3, volume 3, Janeiro - Junho de 2017. 
Quando se trata das temáticas voltadas para o estudo da presença africana no Brasil, a oralidade é o caminho para entender uma série de dados antropológicos que estão na base dos processos de significação e ressignificação que ocorreram no contexto de nossa sociedade, portanto, pensar em conhecimentos afro-brasileiros implica em aplicar uma metodologia de trabalho que articule boca e ouvido.

Segundo Mazzoleni ${ }^{29}$ existe uma contraposição entre oralidade e literalidade que permeia na sociedade ocidental, em que se coloca a oralidade como inferior e a literalidade como superior. A literalidade é entendida como objetiva enquanto a oralidade estaria no plano da subjetividade.

No ocidente este pensamento interfere em todos os processos de formação, isto porque, em especial dentro das escolas, vem se afirmando que: 1) a grande revolução se deu pela escrita; 2) o patrimônio das culturas orais é a memória e o mito, mas o ocidente letrado considera que a ciência é superior e o mito inferior, portanto, a contraposição oralidade mítica/ literalidade histórica, informa que se deve falar de historicização para o ocidente letrado e mítico-ritual para as sociedades não letradas; 3 ) no ocidente letrado o documento escrito se torna mais confiável do que a memória; 4) para alguns, as culturas orais significam um sinal de atraso.

Parece-me que frente a estes quatro movimentos do pensamento ocidentalizado, alguns pesquisadores e pesquisadoras em suas produções monográficas, trataram os dados coletados, excluindo das análises os mitos que foram narrados pelos sujeitos da pesquisa. Portanto, assumem dados de outros tantos pesquisadores/as, que escreveram objetivando estudar outros objetos que não têm a intenção de desvelar os diversos grupos étnicos que vivem no interior das cidades lócus de estudo. Autores que negam e silenciam a presença de alguns grupos para ressaltar outros tantos.

As pesquisas que tomam a oralidade vão requerer do pesquisador que entre no contexto sócio-histórico-cultural para ouvir as exposições verbais. A transmissão destes dados realiza-se pela memória, que seleciona dados para ser lembrado a partir de sua identidade étnica, o que não se torna menos verdade, já que, a cultura escrita também registra o que lhe é conveniente.

\footnotetext{
${ }^{29}$ Mazzoleni, Gilberto. O Planeta Cultural: Para uma Antropologia histórica. Tradução de Liliana Lagená Fernandes. São Paulo: Editora da Universidade de São Paulo: Instituto Italiano di cultura di San Paolo e Instituto cultural Ítalo Brasileiro, 1992.
}

Odeere: revista do programa de pós-graduação em Relações Étnicas e Contemporaneidade - UESB. ISSN 2525- 4715. Ano 2, número 3, volume 3, Janeiro - Junho de 2017. 
A produção de Daniela Silva Santana ${ }^{30}$ teve como objetivo investigar o grau de importância que a comunidade do Terreiro dá à tradição oral, mesmo tendo na sua maioria, membros que dominam a cultura letrada. Esta monografia fora intitulada "O Ilê Axé Odé Yá Minibu: Tradição Oral e a Preservação da Pertença". A professora lançou mão da etnografia, fazendo entrevistas com os membros do terreiro.

Ela descreve o que é a oralidade no terreiro, através dos rituais, mostrando que oralidade é algo maior do que apenas falar. A oralidade se estrutura na experiência do cotidiano do ver/fazer da memória, como guardiã do aprendizado. Destaco aqui uma das suas observações: "no decorrer das festas e durante os rituais a oralidade aparece como principal fonte de ensino". Ela constata que, a oralidade existe como fonte de ensino, se torna responsável pelo ver, sentir, intuir, dizer, calar. Daí ela observar que a oralidade promove a aprendizagem, pois, mesmo tendo um grande número de pessoas dominando o código da escrita no interior do terreiro, os iniciados utilizam os saberes da cultura escrita para registrar o que aprenderam na oralidade.

Nesta constatação, percebe-se o mesmo movimento feito nas sociedades humanas, os conhecimentos das sociedades ágrafas serviram para demonstrar, descrever, enfim, escrever a palavra. Serviram para escrever o que nem sempre consegue ser interpretado.

Só para falar em conflito entre literalidade e oralidade, dado que não foi abordado pela professora, teremos que perguntar: qual o valor que liga realidade à intuição, se em uma determinada cultura, entende-se intuição como superstição? Quais são os valores étnicos que permeiam a discussão de oralidade?

As discussões que envolvem as categorias de análise oralidade e literalidade não podem desprezar as relações étnicas. Assim, o que foi discutido nas duas outras produções que tomamos a seguir, vem ao encontro do que estamos a dizer.

\footnotetext{
${ }^{30}$ SANTANA, Daniela Silva. O Ilê Axé Ode Yá Minibú: Tradição Oral e a Preservação da Pertença. Monografia do Curso de Pós-graduação Lato Sensu em Antropologia com Ênfase em Culturas Afro-brasileira. Universidade Estadual do Sudoeste da Bahia-UESB, Jequié, 2007.
}

Odeere: revista do programa de pós-graduação em Relações Étnicas e Contemporaneidade - UESB. ISSN 2525- 4715. Ano 2, número 3, volume 3, Janeiro - Junho de 2017. 
A produção de Pedro Freire Botelho ${ }^{31}$, intitulada "Ewé Awô: um estudo antropológico sobre as folhas e seus segredos no terreiro Ilê Axé Ogum Megê em Vitória da Conquista/BA", toma a metodologia de "Boca a ouvido", através da categoria oralidade, para pesquisar sobre o conhecimento das folhas presentes no terreiro.

O referido pesquisador vai ouvir dos seus sujeitos de pesquisa: "silêncio é a maneira de conhecer os fundamentos"; um outro afirma: "Nessa tradição a norma principal é escutar (...)"; um terceiro pesquisado diz "Muita curiosidade pode prejudicar, ou como se costuma dizer nos terreiros: quem quer ver muito acaba vendo demais", e, por fim, um quarto pesquisado afirma "o segredo (...) denota compromissos com aquilo que se sabe e se diz".

Temos aí elementos importantes para pensar sobre oralidade. Aparece o silêncio, a escuta, o segredo. Está aí colocada a dinâmica inserida na oralidade, o silêncio e a palavra, o dizer e o calar. Eu ouso dizer que estes três elementos - silêncio, escuta e segredo - são fontes que nutrem os processos de inclusão e exclusão, portanto, as fronteiras étnicas dos grupos no interior do terreiro.

Os fatos não comportam apenas uma verdade, assim como, o vento não sopra só para uma direção, as águas não têm apenas as propriedades de serem incolor, inodora e insípida, elas apresentam outras propriedades particulares que independem de ser rasas ou profundas, por exemplo, a palavra água enuncia infinitas imagens, assim como, a palavra folha e todas as coisas. No dito do entrevistado, pode estar a ideia que um pensamento não abarca tantas diferentes verdades, esta é a riqueza e a ameaça da diversidade.

Nas falas "quem quer ver muito acaba vendo demais" e "o segredo (...) denota compromisso com aquilo que se sabe e se diz", o que se pode também dizer é que está aí colocada uma educação que acredita em vários sentidos que uma mesma coisa pode apresentar.

Silveira $^{32}$ considera que a educação é um processo interacional construído a partir de estratégias e meios utilizados para passar valores às gerações futuras e dessa forma manter o

\footnotetext{
${ }^{31}$ BOTELHO, Pedro Freire. Ewé Awo: Um Estudo Antropológico Sobre As Folhas e Seus Segredos No Terreiro Ilê Axé Ogum Megê Em Vitória Da Conquista - BA. Monografia do Curso de Pós-graduação Lato Sensu em Antropologia com Ênfase em Culturas Afro-brasileira. Universidade Estadual do Sudoeste da Bahia-UESB, Jequié, 2008.

${ }^{32}$ SILVEIRA, Marialda Jovita. A Educação pelo Silêncio: o feitiço da linguagem no candomblé. Ilhéus, Ba: Editus, 2004.
}

Odeere: revista do programa de pós-graduação em Relações Étnicas e Contemporaneidade - UESB. ISSN 2525- 4715. Ano 2, número 3, volume 3, Janeiro - Junho de 2017. 
ethos, a identidade. Nesta discussão, ela coloca que tanto a palavra quanto o silêncio enunciam e são enunciadores, de subjetividades, sentidos, significações.

Uma outra produção vem ao encontro da discussão feita por Silveira, é a monografia de Edneide Alves Nascimento Putumujúi ${ }^{33}$ “O Legado dos Falares Afro-brasileiros em Ipiaú: Um Documento Vivo na Oralidade dos Idosos da Avenida São Salvador - "Fuá"”." Nesta produção a palavra aparece para enunciar e ser enunciadora de história, neste sentido, a autora do texto monográfico entende que a oralidade nas vozes dos mais velhos se fez como veículo de perpetuação da língua e como possibilidade de enxergar a variação dialetal e semântica das palavras.

Ela diz que tomar a história da rua "FUÁ" na cidade de Ipiaú, foi interessante, assim, pôde perceber que de fato as palavras exprimem ideias, características, dizem o jeito de ser, de pensar, de agir de um povo. Logo, as palavras podem abarcar uma história.

A palavra "Fuá" conta a história da presença africana na cidade de Ipiaú. Putumujú, verifica que Castro $^{34}$ traz em seu dicionário que a palavra Fuá é de origem banto. Significa folia, algazarra, fuzarca, muvuca, mafuá, o que se aproxima do que os moradores falam acerca do espaço. Um dos depoimentos de pesquisados afirma: "antigamente aqui nesta mesma rua, havia muita gente bagunceira, eles chamavam empata viagem, dava o nome de Fuá, era lá em baixo (...) era espaço de mulherio, briga, bebedeira (...)".

Putumujú vai argumentar que, em uma sociedade que exclui ou ressignifica as palavras de legado africano, seus significados são tomados na prática, no cotidiano dos sujeitos da pesquisa, através da oralidade.

A palavra afro-brasileira lança imagens sobre outras palavras das línguas africanas no português brasileiro; daí a professora catalogar algumas, umas que foram excluídas, pois são consideradas feias ou gírias, tais como, gororoba, bunda, tabaca, zoeira; outras que foram ressignificadas: "Fuá", dengue, angú, xodó. Sobre as encontradas com outros significados ela afirma que as palavras "passaram a ter não só o significado nas falas dos idosos a partir dos

\footnotetext{
${ }^{33}$ PUTUMUJÚ, Edneide Alves Nascimento. O Legado dos Falares Afro-brasileiros em Ipiaú: Um Documento Vivo na Oralidade dos Idosos da Av. São Salvador- 'FUÁ'. Monografia do Curso de Pós-graduação Lato Sensu em Antropologia com Ênfase em Culturas Afro-brasileira. Universidade Estadual do Sudoeste da Bahia-UESB, Jequié, 2008.

${ }^{34}$ CASTRO, Yeda Pessoa. Falares Africanos na Bahia. Salvador: EDUFBA, 2004 (pág. 56).
} 
significados da base, mas eles se serviram desses significados para expressar (...) sentimentos, pensamentos ou situações", o significado foi deslocado para ter outra função social e cultural de comunicação. Fuá, nome de uma rua na cidade de Ipiaú/BA, fora substituída no endereço oficial catalogado pelos Correios como "Avenida São Salvador". Xodó passou a significar amante na memória dos idosos. Assim, a palavra angú, interpretada pelos idosos, significa pirão, conforme também Castro fala, mas vão além, dizendo que é "coisa mal feita", "uma confusão", "mistura".

Um outro exemplo, a palavra dengue, em Castro, encontra-se como significado de choradeira, birra, manha, treta. Já os pesquisados afirmam que dengue: "é doença, a gente fica mole, manhoso, só na cama com o corpo mole", "inseto", "mosquito da dengue".

Putumujú reforça o que fora argumentado por Botelho em seu texto monográfico, a força que está nas palavras faz com que elas sejam "carregadas da emoção, da história pessoal e do poder daquele que a profere".

Se a palavra enuncia imagens, imagem é algo cultural, portanto, é também pela palavra que podemos pensar em valores étnicos. Esta via de pensamento está nos trabalhos que a oralidade alçou à categoria de teoria /prática. Ao ler a monografia de Putumujú, percebi o trato étnico que ela dá à palavra "Fuá". Também no trabalho de Botelho percebi o mesmo tratamento étnico com a palavra "Folha".

A palavra tem que ser analisada em suas letras, suas sílabas, que reunidas formam uma palavra que vai refletir expressar o que ritualmente ela agrega ou não. É nesta perspectiva que estamos tratando a palavra Legado Africano neste estudo, buscando o que ela enuncia quando para falar de afro-brasileiro, localiza sua identidade no sincretismo, na "dupla pertença" e na mestiçagem.

Cristiane Batista da Silva Santos ${ }^{35}$, em sua monografia intitulada "Encruzilhadas de Saberes: Religiosidade e Dupla Pertença no Camamuzinho (Distrito de Ibirapitanga -BA), utiliza-se do método da etnografia para investigar por que a identidade cultural de Camamuzinho é conformada por valorações negativas. Sua hipótese é que desde a sua origem, este lugar

\footnotetext{
35 SANTOS, Cristiane Batista da Silva. Encruzilhada de Saberes: Religiosidade e Dupla Pertença no Camamuzinho /Distrito de Ibirapitanga/BA. Monografia do Curso de Pós-graduação Lato Sensu em Antropologia com Ênfase em Culturas Afro-brasileira. Universidade Estadual do Sudoeste da Bahia-UESB, Jequié, 2007.
}

Odeere: revista do programa de pós-graduação em Relações Étnicas e Contemporaneidade - UESB. ISSN 2525- 4715. Ano 2, número 3, volume 3, Janeiro - Junho de 2017. 
apresentou uma relação de dupla pertença no dia a dia, nas festas e na religiosidade, daí existe por parte dos moradores de Ubatã e de Ibirapitanga um olhar que negativa o ethos do duplo pertencimento das pessoas.

Ela busca a história da palavra labuta, tão falada pelos mais velhos da comunidade. Inicia concebendo labuta, no sentido de lida, labor e trabalho, só que ao longo da pesquisa, ao verificar como é aplicado o termo, vai descobrindo que desde os mais velhos, trazidos escravizados para o trabalho nas fazendas desta região, o termo labuta, aparece para falar de festa, trabalho e todas as lutas para viver, nascer e morrer.

É labuta, unir a comunidade para arrumar as igrejas e/ou os terreiros, para fazer o caruru de São Cosme e Damião e/ou dos Erês, para arrumar a procissão de Santo Antônio e /ou fazer a feijoada de Ogum. Portanto, labutam os que lavam roupas no Rio de Contas ou no seu tanque particular, as parteiras, as rezadeiras do "cordão de São Francisco", ritual fúnebre feito com "corpo presente".

Em sua produção, Santos, ao falar da labuta, nos induz a pensar que labutar na cidade em que ela pesquisou faz parte do "Nascer com Nanã e curar com Ogum de Ronda". Estas palavras são enunciadoras de uma simbologia que pode ser explicada tomando os processos biológicos, espirituais e culturais da vida. Os sujeitos não são apenas seres biológicos, mas são também, espirituais e culturais.

É a partir da referida simbologia que Silva Santos vai falar sobre uma parteira da cidade e de suas relações com o conhecimento afro-brasileiro. Incorporada no Orixá Nanã, ela recebe os recém-nascidos. Incorporada com o Orixá Ogum, cuida e cura dos doentes que fazem parte de sua comunidade.

Nascer, viver e morrer são fenômenos da vida de qualquer povo e se encontram na estruturação dos conhecimentos universais. Todavia, para singularizar uma determinada comunidade, são seus mitos que entram em ação.

Ao tomar a mitologia africana, verifica-se que Nanã é a mãe criadora, é a mãe terra, é a lama, o barro original. Ela gera e devora seus filhos, uma vez que todos vêm dela e voltam para ela. Assim, Nanã está ligada ao movimento humano de nascer e morrer.

Odeere: revista do programa de pós-graduação em Relações Étnicas e Contemporaneidade - UESB. ISSN 2525- 4715. Ano 2, número 3, volume 3, Janeiro - Junho de 2017. 
Já Ogum está ligado à abertura de possibilidades, as lutas pela vida; daí ele facilitar abrindo os caminhos para a vida. Ogum enquanto legado africano, está ligado aos processos que estão irmanados com o movimento da ordem e desordem decorrentes das lutas e guerras pela vida.

O nascimento, a vida e a morte não são apenas fenômenos da área de conhecimento da biologia conforme nas escolas se ensina/aprende, são também, conhecimentos focados na diversidade étnica. Nascer, viver e morrer depende do ethos de um grupo, entretanto, as coisas, os fenômenos, os fatos geralmente se apresentam naturalizados.

Sendo assim, é muito salutar perguntar/entender, como uma sociedade entende o conhecimento de parteiras, curandeiros, benzedeiras? Como a problemática situando as discussões que envolvem os conhecimentos que alguns chamam de crenças está posta?

O duplo pertencimento dos afro-brasileiros elabora conhecimentos em que sagrado e natureza são a mesma coisa, não lidam com uma concepção de natureza, e sim, diretamente com a natureza. A lama (Nanã) e o ferro (Ogum) são representações da natureza, ao mesmo tempo são heróis civilizatórios no continente africano. Talvez se possa aqui dizer que o duplo pertencimento afro-brasileiro se configura em duplo conhecimento, para estruturar uma lógica que articula objetivo e subjetivo. O que se faz é alertar para o entendimento de que as lógicas étnicas atendem aos significados e concepções acerca dos símbolos que os grupos possuem.

\section{Água e Folha: Atributos Simbólicos dos Elementos da Natureza}

Santana, em sua monografia, ao falar da motivação para fazer o curso de Antropologia com Ênfase em Culturas Afro-brasileiras se reporta às suas memórias, lembrando da história que sua mãe lhe contara sobre um sonho que persistia em que via uma moça bonita vestida de azul nas águas, o que só após seu nascimento, ela, a mãe, descobre que se tratava de Yemanjá.

Neste sonho aparece o simbolismo da água. Eliade nos diz:

Desde a pré-história, o conjunto água-lua-mulher tem sido percebido como o circuito antropocósmico da fecundidade (...) a mulher, a água, o peixe pertencem 
constitucionalmente ao mesmo simbolismo da fecundidade, verificável em todos os planos cósmicos ${ }^{36}$.

Observem que no sonho estão a água, a mulher, simbolismos que falam de fecundidade. Usando estes simbolismos, a pesquisadora falava da forma como sua mãe esperou ela ser fecundada, de sua identidade. Esta lembrança é uma maneira racional de falar de seu nascer e viver de uma forma sensível.

Para os saberes de legados africanos, a água é o elemento da natureza que liga a trindade: Nanã, Yemanjá e Oxum. Neste sentido, sempre que se fala de um tipo de energia aquática, se fala também das outras. Quando alguém diz que precisa mergulhar em águas profundas, é muito diferente de dizer que vai mergulhar em águas rasas. Nanã é a energia das águas do mangue, Yemanjá é a energia das águas do mar e Oxum, são as águas doces, dos rios, das cachoeiras, das fontes. Em língua lorubá, Yemanjá significa Yeye = mãe; eja = peixe. Segundo Ramos:

Yemanjá é a mãe d'água de origem Yorubá, que confluiu no Brasil com as crenças das Sereias de origens européias e as Yaras ameríndias. Na Bahia, Yemanjá, com seus vários nomes: Sereia do Mar, Rainha do Mar, Princesa do Mar, Dona Janaína, Dona Maria.... é festejada (...) em vários pontos do recôncavo, das ilhas e do litoral marítimo. ${ }^{37}$

Tendo como hipótese que uma música, assim como, uma dança, só podem ser consideradas afro-brasileiras se forem enunciadas através de um mito africano, busquei os estudos desenvolvidos pela dançarina Suzana Martins ${ }^{38}$, com a dança de Yemanjá Ogunté. Segundo ela, a escolha por Yemanjá Ogunté, informa ao leitor sobre quais perspectivas estéticas do corpo fará a abordagem.

Ao fazer esta afirmação, Martins diz algo que é do conhecimento de qualquer etnia. As águas são diferentes, uma onda não é igual a outra. A esta diferença nas águas salgadas, o

\footnotetext{
${ }^{36}$ ELIADE, Mircea. Imagens e Símbolos: Ensaios sobre o simbolismo mágico-religioso. Trad. Sonia Cristina Tamer. São Paulo: Martins Fontes, 1991.

${ }^{37}$ RAMOS, Arthur. Introdução à Antropologia Brasileira: As Culturas negras. vol III. Rio de Janeiro, Guanabara: Livraria Editora da Casa do estudante do Brasil (pág 83).

${ }^{38}$ MARTINS, Suzana Maria Coelho. A dança de Yemanjá Ogunté sob a perspectiva estética do corpo. Editora EGBA.Salvador-BA, 2008.
}

Odeere: revista do programa de pós-graduação em Relações Étnicas e Contemporaneidade - UESB. ISSN 2525- 4715. Ano 2, número 3, volume 3, Janeiro - Junho de 2017. 
conhecimento afro-brasileiro enuncia mitos diferentes para diferentes águas. Assim, entre estas águas, lemowô, lamassé, Euá, Olossá, Ogunté, Assabá, Assessu; Martins escolhe Ogunté.

Ela alerta que, falar em dança de Yemanjá remete para o ocidental formado na tradição da ciência universalista, à ideia de que é "uma dança", todavia, é o mito que vai apontar o que come, veste, canta e dança cada uma das Yemanjás.

Na representação simbólica da dança de Yemanjá aparece que andar na água é diferente de andar na terra, assim como dançar quando se tem as duas pernas é diferente de dançar com apenas uma. Neste sentido, os mitos dizem como devem ser dançadas as músicas deste elemento da natureza, e as danças dizem quais palavras estão na música. Portanto, nas letras das músicas constituídas pelo legado africano, estão os atributos simbólicos de um determinado elemento da natureza.

Martins, tomando Rowe, Schelling, afirma que a integração entre a música, a dança e a forma musical, se desenvolve em função da dança, e a dança por si só, se relaciona com a forma musical, assim, elas servem para fazer a comunicação entre o natural e o sobrenatural.

A dança de Yemanjá Ogunté enuncia imagens de movimentos das águas do mar, diferente das danças das outras Yemanjás. São diferentes, as danças das águas dos mangues e das águas doces.

Oxum é a energia contida na água doce das fontes, dos rios. Esta energia se relaciona ao sangue menstrual, à manutenção dos embriões, fetos e crianças durante a gravidez, uma vez que, esses fenômenos são dependentes diretos de líquidos. Portanto, as águas, estão ligadas aos simbolismos da fecundação.

Na Nigéria, "Osun" é a divindade do rio do mesmo nome. Verger, recorrendo a alguns autores, verifica o que dizem os mitos de Oxum na África e aqui no Brasil. Onadele Epega, citado por Verger, vai dizer que:

Osun (...) Nascida em Ekiti Efon, ela é a mãe do Awujale (rei) de ljebu Ere em Ekiti. Mulher de grande valor; gostava da água e nela vivia boa parte do tempo. Nela escondia parte de seus tesouros. Excelente nadadora. O rio onde ela vivia Odo Osun é adorado pelo Awujale de Ijebu Ere (...) Ela foi a primeira fabricante de

Odeere: revista do programa de pós-graduação em Relações Étnicas e Contemporaneidade - UESB. ISSN 2525- 4715. Ano 2, número 3, volume 3, Janeiro - Junho de 2017. 
utensílios de cobre dos Yorubás e do mundo. Seus adoradores usam contas de cobre em torno do pescoço. ${ }^{39}$

Verger observa que na África e na Bahia, como ensinamento do mito, este elemento da natureza "é simbolizado por seixos de rios, sobre os quais são colocados: pulseiras, colares e leques de cobre", objetos de cor amarelos.

O estudo de Macedo ${ }^{40}$, ao analisar como as peças de culturas afro-brasileiras construídas por artesãos nos espaços de terreiros, seguem especificidades de forma e de cor segundo os mitos africanos, ajuda na argumentação de que existem atributos simbólicos enunciados nos mitos.

Assim como vimos o quanto de elementos simbólicos o assunto água carrega, podemos agora verificar atributos simbólicos no assunto folha. Analisando alguns livros didáticos utilizados em nossas escolas, verificamos que este conteúdo é ensinado pelo viés apenas da compreensão de que não passa de um vegetal que está no rol dos seres vivos inanimados, todavia, no cotidiano das pessoas, em muitos momentos, mesmo quando inconscientemente, se atribui estado mental à folha. Podemos dizer que uma pessoa que conversa com suas plantas no seu jardim, atribui à mesma, um estado mental.

No Brasil, a palavra "folha" enuncia uma série de saberes. Saberes de indígenas, saberes de descendentes de africanos fora e dentro do terreiro, saberes dos descendentes de europeus, saberes das rezadeiras, saberes das benzedeiras, saberes nas residências e em muitos outros espaços, como por exemplo, nas escolas.

As rezadeiras não utilizam qualquer folha para rezar alguém, existem folhas específicas. Quando utilizam uma determinada folha para rezar e a mesma murcha, após sua utilização, recebe a explicação de que a folha absorveu energias negativas que estavam rodeando a pessoa rezada. Estaria aí somente o princípio de trocas de energia entre um ser do mundo animado e outro do mundo inanimado?

\footnotetext{
${ }^{39}$ VERGER, Pierre. Notas sobre o culto aos orixás e voduns na Bahia de todos os Santos, no Brasil e na antiga Costa dos Escravos, na África.. Tradução de Carlos Eugênio Marcondes de Moura. São Paulo: Editora da Universidade de São Paulo, 1999. Pág 393.

${ }^{40}$ MACEDO, Roberto Sidnei. Etnopesquisa Crítica, Etnopesquisa-Formação. Editora Liber Livro. São Paulo, 2007.
} 
Para os africanos e seus descendentes, os afro-brasileiros, ao pronunciarem a palavra "folha", há uma ritualização que estabelece uma relação direta entre homem-natureza. A folha não é um ser inanimado, é um elemento sagrado da natureza, neste sentido, ela traz consigo os mitos. Este mito estrutura o saber que se quer evocar sobre a folha naquele determinado momento.

Botelho em sua produção monográfica, seguindo o pensamento de Joana Elbein dos Santos $^{41}$, afirma:

“(...) as folhas, nascidas das árvores constituem uma emanação direta do poder sobrenatural da terra fertilizada pela chuva e, como esse poder, a ação das folhas pode ser múltipla e utilizada para diversos fins. Sendo assim, o uso das plantas depende da intencionalidade da pessoa que a utiliza, portanto a responsabilidade não é do orixá que desperta o poder mágico das ervas, mas da pessoa que as manipula".

Portanto, Botelho ${ }^{42}$ vai dizer que "Percebe-se que na tradição afro-brasileira existe um cuidado todo especial ao recolher as plantas, prefere-se buscá-las pela manhã, quando ainda estão orvalhadas, evitando as ervas que ficam próximas as estradas, a rua". Ele vai observar que existe uma relação de respeito entre aquele que vai retirar essas folhas, solicitando pedido de licença, simbolizando que o homem não é dono da natureza e que as energias presentes nela são forças vivas e atuantes.

Quanto às plantas crescidas na rua, trazem outro tipo de simbolismo; daí ele dizer que o simbolismo da rua revela o movimento por excelência do ir e vir, onde as informações, as pessoas, as energias e todas as coisas circulam, "Coisas boas e coisas ruins, que alegram e também entristecem".

O assunto folha, na vida e no cotidiano dos afro-brasileiros, não interessa apenas para conhecer em quantas partes ela está dividida, é importante entender a sua função. Essa função aparece pela indagação da análise do contexto de uso dentro de um ritual, seja para fazer um remédio, usar para fazer um alimento, fazer chás, fazer banho, para construir objetos para

\footnotetext{
${ }^{41}$ SANTOS, Joana Elbein dos. Os Nagô e a Morte. Petrópolis. Vozes, 1986. Pág 62.

42 BOTELHO, Pedro Freire. Ewé Awo: Um Estudo Antropológico Sobre As Folhas e Seus Segredos No Terreiro Ilê Axé Ogum Megê Em Vitória Da Conquista - BA. Monografia do Curso de Pós-graduação Lato Sensu em Antropologia com Ênfase em Culturas Afro-brasileira. Universidade Estadual do Sudoeste da Bahia-UESB, Jequié, 2008. Pág 32.
}

Odeere: revista do programa de pós-graduação em Relações Étnicas e Contemporaneidade - UESB. ISSN 2525- 4715. Ano 2, número 3, volume 3, Janeiro - Junho de 2017. 
proteção e/ou ornamentação ou qualquer outra serventia. Estes rituais trazem enunciação de palavras específicas, a partir de uma determinada função da folha.

Marcos Aurélio Oliveira $\mathrm{Luz}^{43}$, apud Botelho trabalhando com o sentido de folha nas culturas afro-brasileiras, afirma que, assim como, as penas dos grandes pássaros e as escamas dos peixes simbolizam descendência de princípios femininos, as folhas representam descendência masculina.

Ainda em Luz, apud Botelho, vai dizer que Opa-Ossãiyn, símbolo que representa a folha nas culturas afro-brasileiras, é representado por um símbolo no formato de uma haste de ferro, tendo um pássaro forjado na extremidade superior. Tais hastes representam uma árvore com sete ramos saindo da terra ou da cabeça (ventre fecundado), chamado de igbá-nla, em que se processa o mistério do nascimento.

Se a utilização de uma folha é para curar uma determinada doença, existem mitos que vão enunciar qual o ritual de retirada de uma folha para este fim, hora, cor, forma, tamanho. Todos estes elementos emitem simbologias, imagens importantes.

Na música, Maria Bethânia canta, "cosi ewê, cosi orixá", isto é, "se não há folha, não há orixá". Nesta música se emprega a folha, a condição de que ela lança imagens sobre a natureza e tudo que nela existe. Por se atribuir estado mental à mesma, os afro-brasileiros entendem que a folha deve ser reverenciada, daí sua saudação é Ewé O! Ewé O! (Oh! As folhas! Oh! As folhas!).

\section{Conclusão Inconclusa: Formas simbólicas apontam conteúdos étnicos}

Imagem leva ao sentido, o poder de significação que alguém tenha dessas imagens no interior de suas experiências. O sentido e a concepção que se têm acerca de um determinado símbolo é fruto de experiências provenientes das aprendizagens. Aprendizagens que ligam ao problema da interpretação, da forma como olhamos para um determinado símbolo, para uma determinada imagem.

\footnotetext{
${ }^{43}$ LUZ, Marco Aurélio de Oliveira. Agadá: dinâmica da civilização africanabrasileira. 2a Edição. Salvador: EDUFBA, 2000.
}

Odeere: revista do programa de pós-graduação em Relações Étnicas e Contemporaneidade - UESB. ISSN 2525- 4715. Ano 2, número 3, volume 3, Janeiro - Junho de 2017. 
Paul Ricoeur ${ }^{44}$ em "O Conflito das Interpretações", falando sobre a problemática que envolve a simbólica do mal nas culturas ocidentais, vai dizer que refletir sobre a significação é reencontrar as intenções dos conceitos, por isso, "é preciso destruir o conceito como conceito para compreender a intenção do sentido". Ele diz que a sentença "O símbolo dá o que pensar", é uma sentença que lhe encanta, isto porque, não se põe sentido no símbolo, é ele que dá o sentido.

Eliade ${ }^{45}$ diz que um autor não esgota o sentido de sua obra, assim como um símbolo não esgota para os diferentes julgamentos o seu sentido interpretativo. Mas também ele vai dizer que "os simbolismos arcaicos reaparecem espontaneamente, mesmo nas obras de autores "realistas" que ignoram tudo de tais símbolos". O estudo de símbolos, mitos e ritos revelam sempre uma situação-limite do homem, e não apenas uma situação histórica. Ele diz que "situação-limite é aquela em que o homem descobre tomando consciência do seu lugar no universo", e ainda, "As imagens, os arquétipos, os símbolos são diversamente vividos e valorizados: o produto dessas múltiplas atualizações constitui em grande parte os "estilos culturais"”. As culturas se assemelham, têm suas morfologias e são constituídas em seus próprios estilos, podendo, no entanto, ser comparadas no nível das imagens e dos símbolos.

Busquei interpretar os dados coletados nas produções monográficas, tendo muito cuidado no processo de reinterpretá-los, pois, como diz Thompson ${ }^{46}$, toda interpretação é interpretação da interpretação. Também, busquei analisar as motivações para investigar o objeto de estudo escolhido, assim como, as relações do/a pesquisador/a com as cidades contexto das pesquisas. Neste sentido, tomei os dados das produções monográficas, entendendo que os mesmos são enunciadores da forma como os símbolos carregam elementos material e imaterial de re-produção cultural dos diferentes grupos étnicos.

\footnotetext{
${ }^{44}$ RICOEUR, Paul. O Conflito das Interpretações. Tradução de M. F. Sá Correia; Portugal: Rés- Editora, 1998. Pág 265.

${ }^{45}$ ELIADE, Mircea. Imagens e Símbolos: Ensaios sobre o simbolismo mágico-religioso. Trad. Sonia Cristina Tamer. São Paulo: Martins Fontes, 1991. Pág 172.

${ }^{46}$ THOMPSON, John B. Ideologia e Cultura Moderna. Teoria social crítica na era dos meios de comunicação de massa. Petrópolis, Rio de Janeiro. Ed. Vozes, 1995.
}

Odeere: revista do programa de pós-graduação em Relações Étnicas e Contemporaneidade - UESB. ISSN 2525- 4715. Ano 2, número 3, volume 3, Janeiro - Junho de 2017. 
Segundo Carneiro da Cunha ${ }^{47}$, ao indagar sobre a substância da etnicidade aparecem as categorias raça, culturas, grupos étnicos e identidade étnica.

Carneiro da cunha (idem), baseada nas teorias de Marx Weber sobre comunidades étnicas e em Fredrik Barth com os estudos das fronteiras, vai dizer que a etnicidade enquanto forma de organização política exacerba a cultura de um determinado grupo étnico e também a sua identidade, mas o certo é que não podemos definir grupos étnicos a partir de sua cultura, embora a cultura entre de modo essencial na etnicidade.

$\mathrm{Na}$ etnicidade entram outros elementos além da cultura. Embora sejam interligados, podemos didaticamente destaca-los para melhor compreendê-los. As fronteiras com suas inclusões e exclusões, os traços característicos de cada grupo étnico (religião, roupas, língua, mitos/ritos) e as suas ideologias.

Sendo assim, o trabalho de orientação permitiu que os orientandos/as abordassem sobre os temas, indicando alguns caminhos de racializações culturais encontradas nas relações entre os grupos étnicos que estão no interior das cidades lócus das suas pesquisas. Uns tomaram estas relações apenas para sinalizar posições dos diversos grupos das cidades, outros fizeram reflexões interessantes, apontando processos de mestiçagem e dupla pertença, bem como, fronteiras. Uma das fronteiras está ligada aos elementos de legados africanos, como por exemplo, os mitos africanos e afro-brasileiros.

A proposta de construir conhecimentos por meio da Antropologia com Ênfase em Culturas Afro-brasileiras nas produções monográficas foi importante, pois, tais produções nos apontaram que esta área do conhecimento se municia de categorias que estão no seio dos espaços de cultos religiosos de matriz africana para dar conta de pensar no espaço acadêmico, como é o caso da categoria, Legado Africano.

\footnotetext{
${ }^{47}$ CUNHA, Manuela Carneiro da. Antropologia do Brasil. Editora Brasiliense. São Paulo, 1986.
} 


\section{Bibliografia}

BASTIDE, Roger. Os Candomblés da Bahia rito Nagô. São Paulo: Companhia das Letras, 2001.

BOTELHO, Pedro Freire. Ewé Awo: Um Estudo Antropológico Sobre As Folhas e Seus Segredos No Terreiro llê Axé Ogum Megê Em Vitória Da Conquista - BA. Monografia do Curso de Pós-graduação Lato Sensu em Antropologia com Ênfase em Culturas Afro-brasileira. Universidade Estadual do Sudoeste da Bahia-UESB, Jequié, 2008.

BRAGA, Emanoel Jorge Leal. Baianas do Acarajé: O Que Resta do Mito Africano nos Tabuleiros do Comércio Jequieense. Monografia do Curso de Pós-graduação Lato Sensu em Antropologia com Ênfase em Culturas Afro-brasileira. Universidade Estadual do Sudoeste da Bahia-UESB, Jequié, 2009.

CASTRO, Yeda Pessoa. Falares Africanos na Bahia. Salvador: EDUFBA, 2004.

CUNHA, Manuela Carneiro da. Antropologia do Brasil. Editora Brasiliense. São Paulo, 1986.

ELIADE, Mircea. Imagens e Símbolos: Ensaios sobre o simbolismo mágico-religioso. Trad. Sonia Cristina Tamer. São Paulo: Martins Fontes, 1991.

FERREIRA, Edson Dias. Fé e Festa nos Janeiros da Cidade de Salvador-Bahia. Tese de doutorado defendida na Pontifícia Universidade Católica de São Paulo. São Paulo, 2004.

GEERTZ, Clifford. O Saber Local: novos ensaios em antropologia interpretativa; tradução de Vera Mello Joscelyne. Petrópolis, RJ: Vozes, 1997.

GUIMARÃES, Dinamérica Alves Teixeira. Contribuições do Grupo Capoeira Angola Palmares Para a Formação Cultural da Cidade de Jequié/Ba com a Dança Maculelê. Monografia do Curso de Pósgraduação Lato Sensu em Antropologia com Ênfase em Culturas Afro-brasileira. Universidade Estadual do Sudoeste da Bahia-UESB, Jequié, 2007.

JOLY, Martine. Introdução à Análise da Imagem. Tradução Marina Appenzeller. Campinas, SP: Papirus, 1996- (coleção ofício de Arte e Forma).

LUZ, Marco Aurélio de Oliveira. Agadá: dinâmica da civilização africanabrasileira. 2a Edição. Salvador: EDUFBA, 2000.

MACEDO, Roberto Sidnei. Etnopesquisa Crítica, Etnopesquisa-Formação. Editora Liber Livro. São Paulo, 2007. 
MARTINS, Suzana Maria Coelho. A dança de Yemanjá Ogunté sob a perspectiva estética do corpo. Editora EGBA.Salvador-BA, 2008.

MAZZOLENI, Gilberto. O Planeta Cultural: Para uma Antropologia histórica. Tradução de Liliana Lagená Fernandes. São Paulo: Editora da Universidade de São Paulo: Instituto Italiano di cultura di San Paolo e Instituto cultural Ítalo Brasileiro, 1992.

PUTUMUJÚ, Edneide Alves Nascimento. O Legado dos Falares Afro-brasileiros em Ipiaú: Um Documento Vivo na Oralidade dos Idosos da Av. São Salvador- 'FUÁ'. Monografia do Curso de Pósgraduação Lato Sensu em Antropologia com Ênfase em Culturas Afro-brasileira. Universidade Estadual do Sudoeste da Bahia-UESB, Jequié, 2008.

QUERINO, Manuel. Costumes africanos no Brasil. Organização e prefácio de Raul Lody. Recife: FUNDAJ, Editora Massangana, FUNARTE, 1988.

RAMOS, Arthur. Introdução à Antropologia Brasileira: As Culturas negras. vol III. Rio de Janeiro, Guanabara: Livraria Editora da Casa do estudante do Brasil. 1978.

RODRIGUES, Nina. O Animista Feitchista dos Negros Baianos . Rio de Janeiro: Civilização Brasileira S. A. , 1935.

SANTANA, Daniela Silva. O Ilê Axé Ode Yá Minibú: Tradição Oral e a Preservação da Pertença. Monografia do Curso de Pós-graduação Lato Sensu em Antropologia com Ênfase em Culturas Afrobrasileira. Universidade Estadual do Sudoeste da Bahia-UESB, Jequié, 2007.

SANTANA, Marise de. ODEERE: Formação docente, linguagens visuais e legados africano no Sudoeste baiano. Vitória da Conquista: Edições UESB, 2014.

O Legado Africano na Diáspora e o Trabalho Docente: Desafricanizando para Cristianizar. Tese de doutorado. PUC, 2004.

- O Africano e o Trabalho Docente IN: Inclusão Social, Identidade e Diferença: Perspectiva Pósestruturalistas de análise social. (Orgs) Amaral Jr., Aécio / Burity, Joanildo de A. São Paulo: Annablume, 2006.

SANTOS, Cristiane Batista da Silva. Encruzilhada de Saberes: Religiosidade e Dupla Pertença no Camamuzinho /Distrito de Ibirapitanga/BA. Monografia do Curso de Pós-graduação Lato Sensu em Antropologia com Ênfase em Culturas Afro-brasileira. Universidade Estadual do Sudoeste da BahiaUESB, Jequié, 2007.

SANTOS, Juana Elbein dos. Os Nagôs e a morte: Padê , Asésé e o culto Égun na Bahia. Petrópolis: Vozes, 1976. 
SOUZA, João Nascimento de. Preservação do Legado Africano Pelas Mulheres Negras de Itagibá. Monografia do Curso de Pós-graduação Lato Sensu em Antropologia com Ênfase em Culturas Afrobrasileira. Universidade Estadual do Sudoeste da Bahia-UESB, Jequié, 2010.

SANTOS, Valdinéia de Oliveira dos. Um Lugar para o Orixá: A Saga de Quem Busca Candomblé Fora de Sua Cidade. Monografia do Curso de Pós-graduação Lato Sensu em Antropologia com Ênfase em Culturas Afro-brasileira. Universidade Estadual do Sudoeste da Bahia-UESB, Jequié, 2007.

SANTOS, Zuleide Maria dos. O Trabalho do docente nas aulas de história e culturas Africanas e Afro-brasileira em Camamuzinho - Ibirapitanga - BA. Monografia do Curso de Pós-graduação Lato Sensu em Antropologia com Ênfase em Culturas Afro-brasileira. Universidade Estadual do Sudoeste da Bahia-UESB, Jequié, 2010.

SILVEIRA, Marialda Jovita. A Educação pelo Silêncio: o feitiço da linguagem no candomblé. Ilhéus, Ba: Editus, 2004.

SANTANA, Daniela Silva. O Ilê Axé Ode Yá Minibú: Tradição Oral e a Preservação da Pertença. Monografia do Curso de Pós-graduação Lato Sensu em Antropologia com Ênfase em Culturas Afrobrasileira. Universidade Estadual do Sudoeste da Bahia-UESB, Jequié, 2007.

PUTUMUJÚ, Edneide Alves Nascimento. O Legado dos Falares Afro-brasileiros em Ipiaú: Um Documento Vivo na Oralidade dos Idosos da Av. São Salvador- 'FUÁ'. Monografia do Curso de Pósgraduação Lato Sensu em Antropologia com Ênfase em Culturas Afro-brasileira. Universidade Estadual do Sudoeste da Bahia-UESB, Jequié, 2008.

RICOEUR, Paul. O Conflito das Interpretações. Tradução de M. F. Sá Correia; Portugal: Rés- Editora, 1998.

THOMPSON, John B. Ideologia e Cultura Moderna. Teoria social crítica na era dos meios de comunicação de massa. Petrópolis, Rio de Janeiro. Ed. Vozes, 1995.

VERGER, Pierre. Notas sobre o culto aos orixás e voduns na Bahia de todos os Santos, no Brasil e na antiga Costa dos Escravos, na África.. Tradução de Carlos Eugênio Marcondes de Moura. São Paulo: Editora da Universidade de São Paulo, 1999.

Marise De Santana: Doutorado em Programa de Estudos Pós Graduados em Ciências Sociais pela Pontifícia Universidade Católica de São Paulo, Brasil(2004), Professora Nível Pleno da Universidade Estadual do Sudoeste da Bahia, Brasil

Artigo recebido para publicação em: Maio de 2017. Artigo aprovado para publicação em: Junho de 2017.

Odeere: revista do programa de pós-graduação em Relações Étnicas e Contemporaneidade - UESB. ISSN 2525- 4715. Ano 2, número 3, volume 3, Janeiro - Junho de 2017. 